\title{
IT technology in the management of the modern educational organization: implementation strategies and development
}

\author{
Nataliya Gorbunova* and Elena Ponomareva \\ V.I. Vernadsky Crimean Federal University, Prospekt Vernadskogo, 4, 295007 Simferopol, Russia
}

\begin{abstract}
The article discusses the specifics of the management of a modern educational organization through the application of various innovative technologies. Thus it concentrates on IT technology, which represent a special stage of technological progress. The organizational and management activities by applying such technologies in the implementation and development process of these technologies for the educational and morale building activities of the modern teacher are being considered. Strategies for introducing and developing IT technology into the modern educational process are defined. The research resulted in comprehensive analytical conclusion, based on a survey aimed at future teachers, managers in education as well as students of different fields of training. In the course of the research, there was a survey conducted on "The application of IT technology in the modern educational process: factors of influence and effect" among students and graduates of the Federal Autonomous Education Institution of Higher Education "Crimean Federal University named after V.I. Vernadskiy". Respondents were 265 students and 120 teachers.
\end{abstract}

\section{Introduction}

The education system provides for a special interest in oneself from various related structures, which complement and expand its capabilities in both functional and operational senses. At the same time, the educational structure itself also influences social institutions as well as they have on it, which illustrates the principle of cyclicity and the close relationship of all elements of sociocultural space with each other. Thus, as a flexible and changeable structure, education is constantly in need of seeding base of opportunities to influence society. Important tools are the products of technical and informational progress, which are active mechanisms for managing social thinking.

At the same time, today modern information technologies are not only tools that complement and enrich the education system as well as many of its structural elements by scientific and educational knowledge, but also are the regulator of new ways of knowledge of its certain structures. In social term information technology offers opportunities to expand and enrich the virtual space in which virtual communication is carried out. The

\footnotetext{
*Corresponding author: viza_1986@ukr.net
} 
attitude of representatives of different social institutions toward it varies, because virtual space is not suitable for everyone. However, the educational structure is particularly interested in implementing such technology in the organization and management of the educational process, which actualizes the research of their impact on all kinds of educational process. In addition, the implementation of such technology into the educational environment requires the modernization of all other areas. The fact is that education is closely linked to all the existing social institutions (5). Communication needs to be maintained regularly and productively and informational technologies must be used for this purpose. It is important to understand that, IT has a number of advantages and disadvantages like any other field that need to be taken into account when choosing certain elements.

The main shortages of IT technology implementation are:

Costs for regular equipment, software upgrade, and staff training. At the same time, the costs reflect significant limitation of external financing from the state. The manager of an educational organization must understand that even the latest technical means require updating and addition. They aim to regularly replenish the technical and information base of the world's technical potential. In this regard, costs require special attention;

-Barriers in the psychology of some participants of the educational process, which show themselves in the form of lack of confidentiality as well as fear of technology. The most important psychological barrier is the lack of theoretical and practical knowledge of the informational nature. The manager should focus on the modernization of education and teaching staff, which should contribute to this modernization through the application of the latest knowledge and skills in the organization of the educational process;

-Absence or lack of skills in dealing with such technologies, as well as low digital literacy among the teaching staff. It is important to understand that such technology should be aimed not only at improving organizational and management activities in the educational process, but also in enriching the teaching staff with the latest knowledge as well as providing opportunities for them to improve skills and digital literacy.

The application of technology requires taking into account the importance of its evaluation. It should be based on certain, previously formed models that greatly help researchers and practitioners to define the problem series and evaluate the effectiveness of innovation, promote reasonable choice of teaching methods and management of an educational institution. In addition, the evaluation is critical and helps identify shortages and advantages in the digital environment.

Such technologies are also necessary to motivate employees to carry out professional and management activities in educational institution. Thus, the evaluation and reflection of the technologies used allows to generate a certain range of problems that can affect the motivation of employees (8). It should be noted that any risks are justified by the ultimate goal. It is important to learn how to manage not only technologies, but also modifiable factors that influence the management structure of an educational organization.

It is also necessary to define the main strategic elements that are part of the information technology structure used in the educational process. These include:

Distance education technologies that allow to establish contact and interpersonal communication with various subjects of educational activities as well as to pass information from a distance;

Communications networking technologies that create a single digital environment to make a network that allows all elements of the digital environment to function within a single chain;

Digital security management technologies aimed at regulating the management activities of an educational institution; 
-Creating the logistics of an educational institution through the widespread introduction of computers with universal access to all subjects of the educational process;

-To develop the latest strategies for teaching and learning, education, character building and motivation based on digital literacy and technical awareness of educators and managers of education;

-Active and regular training of staff for managing the educational process and human resources through the latest technologies and digital communications;

-Introducing a variety of online services for the student community;

- creating the concept of administrative systems aimed at systemizing and regulating organizational and management activities based on IT technologies.

According to the list, one can conclude that it can be applied in absolutely any educational institution at different levels. At the same time, it is necessary to assess the current situation by conducting a survey among students of different directions and forms of training, so that to identify the necessity to improve and compensate certain information tools. In the course of the research, there was a survey conducted on "The application of IT technology in the modern educational process: factors of influence and effect" among students and graduates of the Federal Autonomous Education Institution of Higher Education "Crimean Federal University named after V.I. Vernadskiy" Respondents were 265 students and 120 teachers.

\section{Materials and Methods}

The research is based on the survey of students and teachers of different directions and form of education, in which totally more than 200 people, subjects of character building and educational activities participated. The survey was carried out in several stages and aimed at identifying existing gaps in the application of IT technology not only in the educational process, but also in the organizational and management mechanism, which will allow to formulate the latest concepts of the strategy of implementation of such technologies in future. The survey was aimed at different age groups to discover dispositions to apply information technology in the learning process as well as find out local problems in this area.

The purpose of the research was to determine existing problems in application of IT technology, explore existing strategies for introducing such technologies into the organizational and management mechanism of the educational institution as well as comprehensive analysis of the experience for applying such technologies in practice.

\section{Results and Discussion}

The results of the survey showed that $47.4 \%$ of teachers surveyed believe that information technology has a negative rather than positive impact on the educational process. At the same time, $37.8 \%$ have the opposite opinion that application of such technologies is necessary and even obligatory for the implementation of the most effective and working pedagogical activity of any modern teacher. In the latter case, the activity was mainly shown by teachers under age of 35 , which confirms the theory of unpreparedness of the older generation to switch to digital type of education. At the same time, $82.4 \%$ of all students surveyed agree that distance education technologies and other information technologies are highly effective and necessary means of obtaining educational services. Out of these, $55 \%$ believe that the most important and convenient technology is distance education, which does not require attending educational institution, while the remaining roughly $45 \%$ welcome only partial introduction of information technology into the classical 
educational process. There is clearly a significant difference in opinions regarding application of such technologies. Most educators do not still approve new ways of transfering information and personal experience as well as managing educational activities.

As part of the same research, satisfaction with the existing base of IT technology used in the training was determined at the Federal State Autonomous Educational Institution of Higher Education "Crimean Federal University named after V.I. Vernadsky," which allowed us to outline a certain range of problems to be solved in terms of management and organizational activities. The results of this survey are shown in Tables 1 and 2.

Table 1. Satisfaction with the existing base of IT technology used in the educational and organizational and management activities of the university (\%).

\begin{tabular}{|l|c|c|c|c|}
\hline & $\begin{array}{c}\text { Partial Satis } \\
\text { faction }\end{array}$ & $\begin{array}{c}\text { Absolute satis } \\
\text { faction }\end{array}$ & $\begin{array}{c}\text { Partial } \\
\text { dissatisfaction }\end{array}$ & $\begin{array}{c}\text { Absolute } \\
\text { dissatis } \\
\text { faction }\end{array}$ \\
\hline $\begin{array}{l}\text { The whole logistics of the } \\
\text { educational process }\end{array}$ & 8.3 & 12.5 & 40 & 49.2 \\
\hline $\begin{array}{l}\text { Logistics of the } \\
\text { educational process of } \\
\text { special disciplines }\end{array}$ & 10.4 & 8.5 & 55.5 & 26.6 \\
\hline $\begin{array}{l}\text { General level of } \\
\text { pedagogical proficiency } \\
\text { in technical equipment }\end{array}$ & 23.5 & 20.1 & 27.2 & 29.2 \\
\hline $\begin{array}{l}\text { Applying the latest } \\
\text { technologies, innovative } \\
\text { forms in education }\end{array}$ & 4 & 16.1 & 56.7 & 33.1 \\
\hline $\begin{array}{l}\text { Implementation of } \\
\text { organizational and } \\
\text { management activities } \\
\text { through IT technology }\end{array}$ & 39 & 43.1 & & \\
\hline $\begin{array}{l}\text { Building a digital culture } \\
\text { and mastering the } \\
\text { principles of digital } \\
\text { literacy }\end{array}$ & 12.5 & & & \\
\hline
\end{tabular}

Table 2. Academic teaching staff satisfaction with existing base of IT technology used in the educational and organizational and management activities of the university (\%).

\begin{tabular}{|c|c|c|c|c|}
\hline & $\begin{array}{l}\text { Partial Satis } \\
\text { faction }\end{array}$ & $\begin{array}{c}\text { Absolute satis } \\
\text { faction }\end{array}$ & $\begin{array}{c}\text { Partial } \\
\text { dissatisfaction }\end{array}$ & $\begin{array}{c}\text { Absolute } \\
\text { dissatis } \\
\text { faction }\end{array}$ \\
\hline $\begin{array}{l}\text { The whole logistics of the } \\
\text { educational process }\end{array}$ & 12.5 & 8.2 & 11.1 & 68.2 \\
\hline $\begin{array}{l}\text { Logistics of the educational } \\
\text { process of special } \\
\text { disciplines }\end{array}$ & 63.2 & 20.6 & 9.1 & 7.1 \\
\hline $\begin{array}{l}\text { General level of } \\
\text { pedagogical proficiency in } \\
\text { technical equipment }\end{array}$ & 38.6 & 30.3 & 16.1 & 5 \\
\hline $\begin{array}{l}\text { Applying the latest } \\
\text { technologies, innovative } \\
\text { forms in education }\end{array}$ & 33.1 & 46.8 & 16.1 & 4 \\
\hline $\begin{array}{lr}\text { Implementation } & \text { of } \\
\text { organizational and } \\
\text { management activities } \\
\text { through IT technology }\end{array}$ & 14.5 & 15 & 50.5 & 20 \\
\hline $\begin{array}{l}\text { Building a digital culture } \\
\text { and mastering the } \\
\text { principles of digital literacy }\end{array}$ & 24.2 & 35 & 33.5 & 10 \\
\hline
\end{tabular}


It is interesting to note that the majority of learners have identified a fairly low and unsatisfactory general level of absolutely all aspects and fields of applying information technology in the university, while the teaching staff is unsatisfactory with the implementation of organizational and management activities of the university.

Students emphasize the low level of teaching innovative forms and types of activities in practice and the low level of digital literacy of teachers which indicates that refresher courses should be conducted in this direction. Learners being the center of the educational process, are a highly structured and complex community that actively responds to changes and innovation. Therefore It is necessary to pay special attention to their attitude to certain changes in the structure of education.

It is important to understand that pedagogical and student attitudes to some problems may differ due to many existing causes that form a certain range of unresolved issues facing pedagogical science in future. However, this research proves that objectivity is essential for the most effective interaction between all educational subjects and its organization, management and control.

Based on the survey data, conclusions may be drawn about the most common modern technologies in education, which have found application and response with majority of learners and teachers. Such technologies include:

- using the latest information technologies as the main or additional means of organizing educational activities, which have a great impact on the improvement and progress of the teaching process as well as greatly upgrades the quality and efficiency of this process. As a means of learning, information technology has found the greatest response among students (according to the above survey results), but teachers believe that for this reason the sense of personal contact between the teacher and the student is becoming lost;

-applying such technologies in terms of educational tools, cognitive activities within surrounding community and personality. Information technology is often used as tools, and this approach is more acceptable for educators rather than learners. Regardless of how an individual and his capabilities, potential and skills are perceived, learners often face a high degree of indiscipline and inability to work with information technology independently, which greatly complicates the process of their personal fulfillment and awareness of their place in the sociocultural space in which they develop;

-applying such technologies as the main driving force of the creative development of a learner. Creative development involves the involvement of various thought processes and critical aspects of human thinking. At the same time, creativity may be shown not only in the artistic sense, but also in the scientific and technical sense. Creativity may not always be associated solely with visual, musical, multimedia of creating a piece of work, but also with the formation of concepts, strategies, technologies and mechanisms developed on the basis of certain technical means;

- applying information technology in terms of automation and management, regulation, testing and control of the educational process and all its subjects. The fundamental factor consists in management activities by technical means, aimed at regulating the activities of learners and academic and teaching staff, teaching methods and educational activities;

- forming a new system of interpersonal communications based on application of information technology within transmission, storage, acquisition of some experience, etc. This creates a special communicative culture, which now depends not only on each individual subject, but also on the holistic concept of building an entire network where communication is carried out;

- and finally, the intensification of the management of the educational institution and its educational potential by applying the latest innovative technologies, which contributes to achieving maximum efficiency of management process and regulation of all processes taking place within the organization. 
According to the above survey results, the absolute majority of learners consider the information and technical base of the educational institution inefficient, so it would be fair to mention the need to set the latest concepts of management of the educational organization through the latest progressive management technologies. It is also necessary to pay attention to the current trends and strategies for the formation and development of such technologies in the education field by actively applying various technological advances in modern development.

It is necessary to pay attention to the opinions of both respondents' groups, as this approach will allow to identify existing problems in pedagogical and educational directions, which can considerably contribute to the development of the entire education system of Russia in future.

\section{Conclusions}

Modern information technologies form a core of the digital culture, which is the key feature of the 21 st century. Today, every specialist, regardless of the type of activity, should has a sufficient level of knowledge of technological progress and digitalization accumulated for years. Thus, in view of the flexibility and variability of the education system, we should focus on the experience of applying and developing such technologies in terms of not only organizing educational process, but also its management, regulation and control.

In the course of this research, we have identified a certain pattern, which illustrates some dualism consisting of diametrically opposite opinions of different subjects of educational activities in one university. Thus, teachers and learners do not agree on the logistical and organizational-management provision of the educational process. While teachers believe their level of digital literacy is sufficient but learners have different views.

It is important to understand that such a conflict of opinions should not be considered as an exceptionally negative aspect of organizing an educational process but one must make all efforts to solve problems arising in the process of this clash.

\section{References}

1. O.B. Akimova, M.D. Shcherbin, Innovative projects and programs in education, 1, 27 (2018)

2. M. Podtserob, Vedomosti, 4342 (2017)

3. N.Sh. Kozlova, Actual problems of technical sciences: collection of articles of the International Scientific and Practical Conference, 105 (2015)

4. N.Sh. Kozlova, Bulletin of MSTU, 4, 80 (2018)

5. N.Sh. Kozlova, Digital Economy: a new reality: collection of articles on the results of the International scientific and practical videoconference dedicated to the 25 th anniversary of the university, 45 (2018)

6. N.Sh. Kozlova, Digital Economy: A New Reality: collection of articles on the results of the International scientific and practical videoconference dedicated to the 25 th anniversary of the university, 93 (2018)

7. S.D. Karakozov, A.Yu. Uvarov, Problems of Modern Education, 2, 7 (2016)

8. N.S. Kramarenko, A.Yu. Kvashin, Bulletin of Moscow State Regional University, 4, 1 (2017)

9. V.K. Kapranov, M.N. Kapranova, Open and distance education, 3(47), 28 (2012)

10. J. Piaget, Psychology of intellect (1994)

11. Smart Learning Program for Specialists of the Republic of Kazakhstan Professional development for teachers based on Smart Learning (2014) 
12. F. Yanushkevich, Teaching technology in the system of higher education (1986) 